\title{
EFFECT OF DEGREE OF SULFONATION IN NANOCELLULOSE/CHITOSAN COMPOSITE ON ADSORPTION OF CATIONIC DYE AS OPIOID SIMULANT
}

\author{
MARSHALL FRYE, ${ }^{*}$ SHANGRADHANVA E. VASISTH, ${ }^{*}$ AMALIE ATASSI," \\ DAVID MAZYCK ${ }^{* *}$ and JUAN C. NINO* \\ "Department of Materials Science and Engineering, University of Florida, Gainesville, \\ Florida, 32603, United States \\ *** Department of Environmental Engineering Sciences, University of Florida, Gainesville, \\ Florida, 32603, United States \\ ¿Corresponding author: Marshall Frye, marshallfrye@ufl.edu
}

Received July 8, 2020

In this study, the effect of nanocellulose sulfonate group content on adsorption of an opioid simulant was tested. The opioid simulant used was Victoria blue R, an amine dye. Nanocellulose filters were fabricated by crosslinking cellulose nanocrystals (CNCs) with chitosan to improve the mechanical stability of freeze-dried CNCs. Thermogravimetric analysis confirmed the filter's thermal stability and operating temperatures. Conductometric titration, Fourier transform infrared spectroscopy, and scanning electron microscopy techniques were used to characterize the degree of nanocellulose functionalization. Lastly, the adsorption performance of the sulfonated nanocellulose filter was tested and fitted to kinetic models and adsorption isotherms. The adsorption of the dye by the sulfonated nanocellulose followed pseudo-second order kinetics and the Langmuir isotherm. The maximum adsorption of Victoria blue $\mathrm{R}$ dye by sulfonated nanocellulose $(68.56 \mathrm{mg} / \mathrm{g})$ is significantly higher than those of other adsorbents, like activated carbon $(0.59-2.97 \mathrm{mg} / \mathrm{g})$ and magnetic microparticles $(40.98 \mathrm{mg} / \mathrm{g})$. Thus, sulfonated cellulose nanocrystals are a promising material for the sequestration of opioids from water.

Keywords: nanocellulose, adsorption, opioid, sulfonation

\section{INTRODUCTION}

Access to potable water is one of the largest issues currently faced by both developed and underdeveloped nations. Currently, 1.6 billion people are designated as living under severe water stress, a number that is projected to increase to 3.9 billion by $2050 .{ }^{1}$ Despite designations from the United Nations to make access to water a human right, water contamination remains prevalent worldwide. $^{2}$

Currently, the most common types of water contaminants around the world are agricultural, sewage, oil, and radioactive substances. ${ }^{3}$ However, personal products and pharmaceuticals are an emerging concern for water contamination. ${ }^{4}$ Within the pharmaceutical contaminants, prescription drugs are of particular concern. For example, opioids are some of the most common legally obtained drugs in the United States. The five different opioids that are listed in the 200 most commonly prescribed drugs are: acetaminophen/hydrocodone $\left(9^{\text {th }}\right)$, tramadol $\left(28^{\text {th }}\right)$, oxycodone $\left(58^{\text {th }}\right)$, hydrocodone $\left(82^{\text {nd }}\right)$, and morphine $\left(115^{\text {th }}\right) .^{5}$ The amount in which opioids are prescribed has increased threefold since 1999, with nearly 58 prescriptions for every 100 Americans based on a report by the Center for Disease Control. ${ }^{6}$ This increase in drug access is a global concern for societal problems related to drug addictions. Besides the ongoing health and societal problems related to opioid addiction, ${ }^{7}$ there are two main routes through which opioids get into water: excretion from users or improper disposal into the water system. Results from recent surveys show that approximately $35-50 \%$ of Americans flush medication down the toilet or sink. ${ }^{8}$ These disposal techniques can cause drugs to contaminate drinking water. In a study by Cone et al., ${ }^{9}$ it was found that around $30.3 \%$ of a typical opioid prescription is released without hydrolysis (i.e. breaking down the opioid through reactions with water, typically done using an enzyme) through urine within 36 hours of taking the 
medication. An additional $39.2 \%$ of the dose is released in a hydrolyzed form through the urine. ${ }^{9}$ Several opioids have metabolized forms that are also identical to other pharmaceutical opioids (e.g. hydrocodone metabolizes to hydromorphone and oxycodone metabolizes to oxymorphone). ${ }^{10}$ Recent studies have shown the presence of opioids in water around the world. These concentrations range from $100 \mathrm{ng} / \mathrm{L}$ to over 2000 $\mathrm{ng} / \mathrm{L},{ }^{11-16}$ concentrations at which there have been demonstrated effects in animals, and long term effects on humans are unknown.

The common steps for wastewater treatment around the world are: preliminary treatment (wide bars to remove large contaminants), primary treatment (sedimentation), secondary treatment (activated sludge, aerated basins), tertiary treatment (nutrient removal, filtration), and disinfection (UV light). ${ }^{17}$ In the United States, the most common steps for water treatment are: coagulation and flocculation, sedimentation, filtration (sand, gravel, and activated carbon), and finally disinfection. ${ }^{18}$ Removal rates for some opioids like heroin and morphine are between 70$86 \%$ using conventional water treatments. However, opioids such as 2-Ethylidene-1,5dimethyl-3,3-diphenylpyrrolidine (EDDP) and methadone have removal rates closer to $40 \% .^{14}$ Adverse effects have been observed in animals and embryos, yet short- and long-term effects of low concentrations (ng/L scale) of pharmaceuticals on humans are unknown. ${ }^{19}$ It is not known whether or not different classes of pharmaceuticals have an additive effect on the human body, which would dramatically increase the probability of long term effects. ${ }^{19}$ It has been shown that, at relatively high concentrations, opioids can affect human embryos, and at the low concentrations as found in drinking water, antidepressants can cross the placental barrier in mice. $^{20,21}$ There have not been any studies on whether or not the low concentration of opioids can cross the placental barrier for human embryos. Because of the inefficiency of current wastewater treatments to remove opioids, coupled with the uncertainty in the effects of the low concentration of opioids on humans and the effects on other animals, there is significant interest in developing novel filtration methods to remove opioids from water. Ideally, the filtration method should be based on sustainable materials and processes that require low energy and low water use to fabricate, reuse, and repurpose. A cellulose based filter could provide such opportunity.

Cellulose is one of the most abundant and versatile polymers on the planet. It has a plethora of uses, such as paper, cardboard, and clothing. ${ }^{22}$ In the 1950's, it was discovered that through acid hydrolysis cellulose can be broken down to nanosized crystalline rods, known as cellulose nanocrystals $(\mathrm{CNCs}){ }^{23}$ These $\mathrm{CNCs}$ have several properties that make them an ideal material for adsorption; they are hydrophilic, form nanoscale crystals, have a high surface area, and a capability for a variety of surface modifications. ${ }^{24}$ Oxidizing the nanocellulose creates easily modifiable aldehyde groups within the cellulose chain. ${ }^{25}$ These aldehydes are most often converted to carboxyl groups ${ }^{25}$ sulfonate groups, ${ }^{26-28}$ and imines. ${ }^{29}$ Due to the strong negative charge of the sulfonate groups, sulfonation can be chosen as a method of functionalization to adsorb opioids. Sulfonation of nanocellulose has already been shown to increase adsorption of positively charged metal ions and dyes. ${ }^{30,31}$ An effective and environmentally safe way to oxidize nanocellulose is through periodate oxidation. ${ }^{32}$ The method is green, compared to other methods, as it does not produce halogenated waste and it has been shown that the periodate can be regenerated after the reaction. ${ }^{33}$ Sulfonation was done using sodium metabisulfite, using a method amply described in literature. ${ }^{26,30,31}$ While sodium metaperiodate has not been shown to be recyclable, it is the better alternative when compared to sulfuric and chlorosulfonic acids, which are used in other methods of sulfonation.

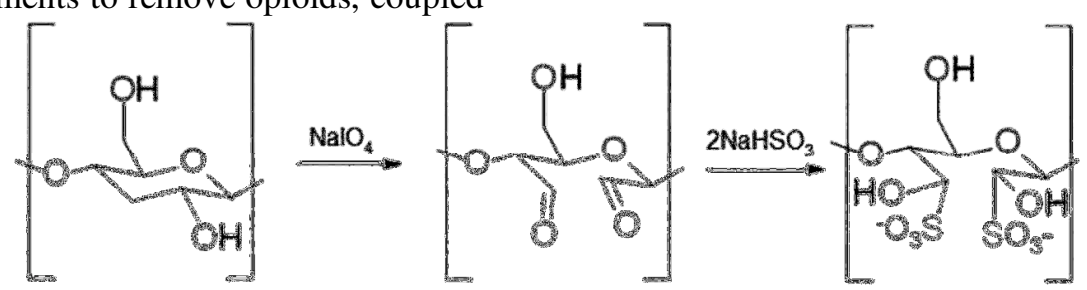

Figure 1: Periodate oxidation and subsequent sulfonation of cellulose ${ }^{33}$ 


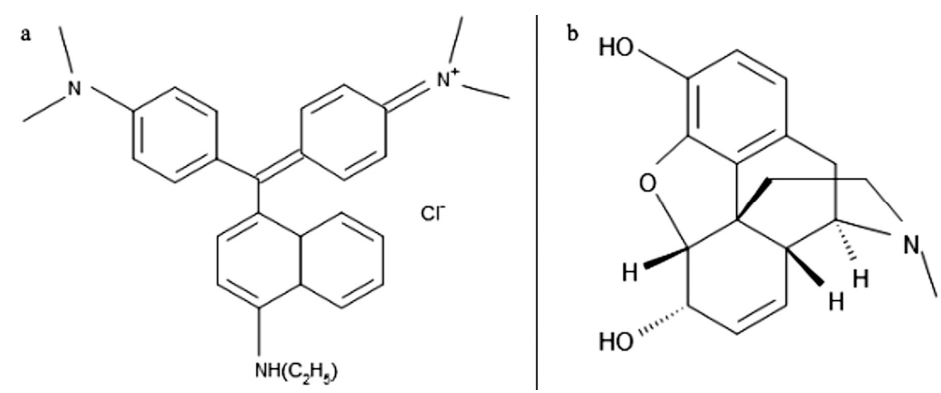

Figure 2: Molecular structure of a) Victoria blue R dye and b) morphine, a typical opioid

Towards the development of a filtration method for the removal of opioids from the water system, here, the potential use of sulfonated nanocellulose as an opioid adsorbent was investigated. We aimed to examine the effect of the degree of sulfonation on the adsorption capacity of the cellulose nanocrystals. It is believed that, if the degree of sulfonation is increased, then the adsorption capacity of the opioid simulant will increase due to the increased electrostatic interactions between the cellulose and the simulant. Actual opioids were not used due to the restrictions on purchasing opioids for research. ${ }^{34}$ In order to simulate an opioid, Victoria blue $\mathrm{R}$ dye was used because of the similarities in the molecular structure. Sulfonation was performed using a periodate oxidation and subsequent sulfonation reaction. The sulfonated nanocellulose was characterized using Fouriertransform infrared spectroscopy (FTIR), thermogravimetric analysis (TGA), scanning electron microscopy (SEM), and conductometric titration. The effect of initial concentration and sorption time on equilibrium adsorption were tested to study the mechanism of adsorption.

\section{EXPERIMENTAL}

\section{Materials}

The chemicals used were: an $8 \% \mathrm{w} / \mathrm{w}$ aqueous solution of cellulose nanocrystals (Blue Goose Biorefineries, Saskatoon, Ca), sodium metaperiodate (99\%, Sigma Aldrich, St. Louis, MO), sodium metabisulfite (99.9\%, VWR International, Radnor, PA), Victoria blue $\mathrm{R}$ (ChemCruz, Dallas, TX), Chitosan (Sigma Aldrich, St. Louis, MO, 75-85\% deacetylated, $\mathrm{MW}=190-310 \mathrm{kDa})$ and sodium hydroxide (Fisher Scientific, Waltham, MA). Because of the lack of a standard opioid simulant for adsorption, Victoria blue R dye was chosen due to its similarities to the structure of many opioids and previous uses in publications looking into adsorption of pharmaceuticals. ${ }^{35,36}$ As shown below, both of the molecules have conjugated carbon rings and tertiary amines. Both of these molecules should have very similar interactions with the negatively charged sulfonate groups. The interaction between the opioid and nanocellulose could be stronger than that of the nanocellulose and the dye due to the increase of polar groups in opioids.

\section{Sulfonation of nanocellulose}

In order to increase the interaction between the dye and the nanocellulose, the nanocellulose was sulfonated. The sulfonation should cause Coulombic interactions, or at least very strong electrostatic interactions, between the sulfonate groups and the positively charged nitrogen in the dye. ${ }^{37}$ Sulfonated nanocellulose was synthesized by periodate oxidation and subsequent sulfonation of the nanocellulose pulps using sodium metabisulfite. This procedure has been shown to be highly effective and more environmentally safe than other methods. To summarize, the nanocellulose pulp was first reacted with sodium metaperiodate with a molar ratio of cellulose:periodate of $1.6: 1$ and a molarity of $0.038 \mathrm{M}$. This reaction occurred for 30 minutes at $55^{\circ} \mathrm{C}$ in the absence of light due to the photosensitivity of the periodate. According to a previous study by J. Sirvio et al. ${ }^{38}$ this reaction will produce an aldehyde group content of 0.614 $\mathrm{mmol} / \mathrm{g}$. The reacted nanocellulose was then washed and centrifuged four times to remove excess periodate. The oxidized nanocellulose was then further reacted with 2.2 times excess moles of $4.8 \mathrm{mM}$ sodium metabisulfite for 4 hours at both room temperature and $45^{\circ} \mathrm{C}$ to vary the degree of sulfonation. The sulfonated nanocellulose was then washed and centrifuged until the conductivity of the supernatant was below 35 $\mu \mathrm{S} / \mathrm{cm}^{2}$ while using a 2:1 (isopropanol:water) v/v solution to ensure precipitation of the nanocellulose. It is important to note that centrifugation of the sulfonated nanocellulose in water did not result in precipitation of the nanocellulose. The samples were then freeze-dried for further characterization and to synthesize filters. The naming of the samples without chitosan is as follows: NF-CNC is nanocellulose without further sulfonation, $4 \mathrm{~h}-\mathrm{CNC}$ samples are ones for which sulfonation occurred at room temperature, 
and $4 \mathrm{~h} 45^{\circ}-\mathrm{CNC}$ samples are ones for which sulfonation occurred at $45^{\circ} \mathrm{C}$. Once crosslinking is performed, $\mathrm{xCh}$ is added to the name (e.g. NF$\mathrm{CNCxCh}$ ).

\section{Fabrication of the filter}

The sulfonated cellulose had very little mechanical integrity post freeze-drying. The samples would break apart during testing and behaved more as a powder than a structured filter. Mechanical testing could not be performed on the non-crosslinked samples because of this brittle condition. To introduce mechanical stability, the freeze-dried nanocellulose was crosslinked with chitosan using a slightly modified technique previously described by Karim et al. ${ }^{37}$ Initially, for each filter, $0.2 \mathrm{~g}$ of $\mathrm{CNC}, 0.0225 \mathrm{~g}$ of chitosan, $45 \mu \mathrm{L}$ of acetic acid, and $4.455 \mathrm{~mL}$ of deionized water were mixed thoroughly and then freeze-dried. The sample was then exposed to glutaraldehyde vapors for 24 hours on each side of the filter in order to induce crosslinking. The glutaraldehyde bonds to the hydroxyl group on the cellulose and the amine group on the chitosan to bind them together. The process in which the cellulose filters were crosslinked is summarized in Figure 3.

\section{Thermogravimetric analysis}

The change in thermal stability due to crosslinking was tested using an SDT-Q600 Simultaneous TGA/DSC instrument. The temperature range measured was from $30-800{ }^{\circ} \mathrm{C}$, with a heating rate of $10{ }^{\circ} \mathrm{Cmin}^{-1}$, using ASTM standard E2550-17. ${ }^{39}$ The TGA was conducted in an argon atmosphere. The extrapolated onset temperature was found using ASTM E2250-17, ${ }^{39}$ and all samples were run in duplicate to ensure that the data was representative of the bulk.

\section{Fourier transform infrared spectroscopy (FTIR)}

This technique was performed on nonfunctionalized, periodate oxidized, and sulfonated samples of nanocellulose, all of which were previously freeze-dried. Spectra in the range of $600-4000 \mathrm{~cm}^{-1}$ were collected using a Thermo Fisher Nicolet 6700 FTIR with an ATR accessory. A minimum of two spectra were collected for each different sample type to verify accuracy and repeatability, and used to test if any changes had occurred during the oxidation and sulfonation steps.

\section{Scanning electron microscopy (SEM)}

SEM was performed on the nonfunctionalized, 4h$\mathrm{CNC}$, and $4 \mathrm{~h} 45^{\circ}-\mathrm{CNC}$ samples, all with and without chitosan. JEOL JCM-5000 Neoscope was used to capture the images. Besides general imaging at microscopic level, the goal of SEM was to observe changes in the layering morphology of the freeze-dried nanocellulose, as the arrangement would vary with a change in the intermolecular forces. ${ }^{40}$

\section{Mercury intrusion porosimetry}

Pore size distribution, volume, and surface area were determined via mercury intrusion porosimetry (MIP), using a Quantchrome Poremaster Mercury Porosimeter. The temperature was set to $20{ }^{\circ} \mathrm{C}$ and the pressure was varied in the range of 0.0194-412 MPa. Pore size and surface area were automatically calculated using the Washburn and Rootare-Prenzlow equations, respectively. Porosimetry was performed on 4h-CNCxCh and NF-CNCxCh samples to determine if pore size is affected by sulfonation.

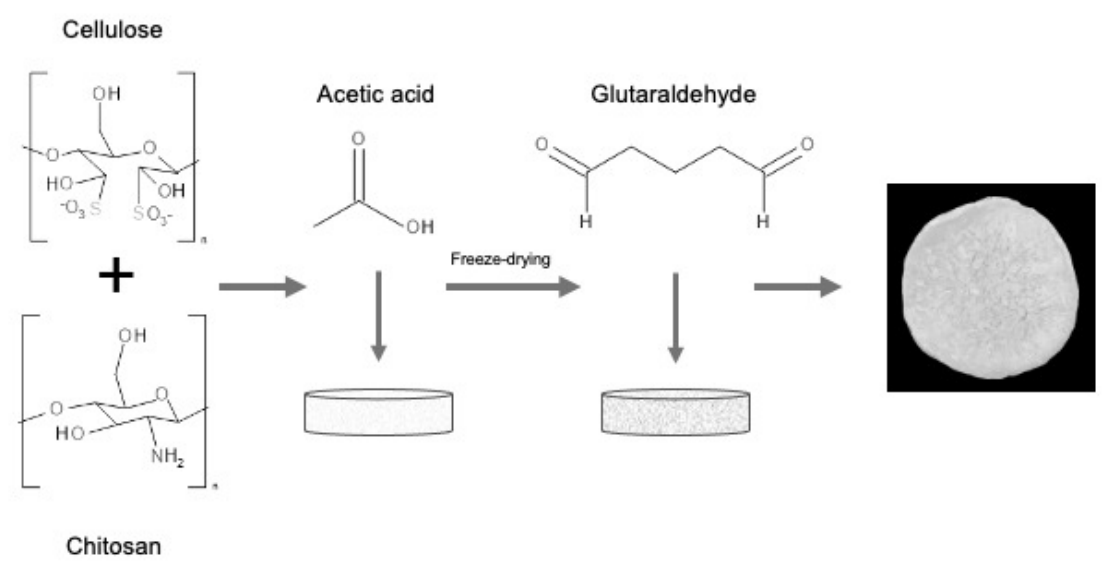

Figure 3: Summary of the crosslinking procedure between cellulose and chitosan

\section{Sulfonate group content}

The sulfonate group content was determined using the conductometric titration method described in SCAN standard CM 65:02. ${ }^{41}$ During the titration, the sulfonate groups react with added sodium hydroxide, as shown in Equation 1:

$\mathrm{CNC}-\mathrm{SO} 3 \mathrm{H}+\mathrm{NaOH} \rightarrow \mathrm{CNC}-\mathrm{SO} 3-\mathrm{Na}++\mathrm{H} 2 \mathrm{O}$ 
To ensure the sulfonate groups are attached to a hydrogen, the $\mathrm{CNC}$ must be protonated. This was done by adding $1 \% \mathrm{HCl}$ to the nanocellulose for 15 minutes. Then, the sample was washed several times using centrifugation and later freeze-dried. The protonated nanocellulose was then added to a solution of $\mathrm{NaCl}$ and water, and mixed. Finally, a constant volume of $0.025 \mathrm{M} \mathrm{NaOH}$ was repeatedly added to the solution and the conductivity of the solution was measured after each addition. The conductivity was measured using a Fisher Scientific Traceable Expanded Range Conductivity Meter. The conductivity was then plotted against the moles of $\mathrm{NaOH}$ added to determine the intersection point at which all strong acid groups have reacted with the sodium hydroxide. From this point, the number of sulfonate groups per gram can be calculated using the equation:

$\mathrm{X}=\frac{\mathrm{M}}{\mathrm{m}}$

where $\mathrm{X}$ is the sulfonate group content $(\mathrm{mmol} / \mathrm{g}), \mathrm{M}$ is the moles of $\mathrm{NaOH}$ added ( $\mathrm{mmol}$ ), and $\mathrm{m}$ is the dry mass of the nanocellulose $(\mathrm{g})$.

\section{Adsorption kinetics}

The adsorption capabilities of functionalized and nonfunctionalized filters were tested by cycling Victoria blue $\mathrm{R}$ dye through the filter. The stock solution of dye was $400 \mathrm{~mL}$, at a concentration of 1 $\mathrm{mg} / \mathrm{L}$ and a $\mathrm{pH}$ of $5 \pm 0.25$. This $\mathrm{pH}$ was chosen based on previous work by Karim et al. ${ }^{39}$ The filters were placed in a PVC column with a wire mesh to keep the filter in place. The dye was then pumped out of the reservoir at $58 \mathrm{~mL} / \mathrm{min}$ using a Cole-Parmer Masterflex peristaltic pump, then through the filter, and finally back into the reservoir. Then, $5 \mathrm{~mL}$ samples of the dye were collected at specific time intervals. These samples were then analyzed using a PerkinElmer Lambda 800 UV/Vis spectrometer. The amount of dye adsorbed at specific times, $\mathrm{q}_{\mathrm{t}}(\mathrm{mg} / \mathrm{g})$, and the adsorption capacity, $\mathrm{q}_{\mathrm{e}}(\mathrm{mg} / \mathrm{g})$, were calculated using the following equations:

$$
\begin{aligned}
& q_{t}=\frac{\left(C_{0}-C_{t}\right) \times V}{m} \\
& q_{e}=\frac{\left(C_{0}-C_{e}\right) \times V}{m}
\end{aligned}
$$

where $C_{0}$ and $C_{e}$ are adsorbate initial and equilibrium concentrations $(\mathrm{mg} / \mathrm{L}), C_{t}$ is the concentration at a specific time $(\mathrm{mg} / \mathrm{L}), m$ is the dry weight of the adsorbent $(\mathrm{g})$, and $V$ is the volume of the solution (L).

The results were then analyzed using pseudo-first and pseudo-second order kinetic models. The pseudofirst order equation is described by:

$\ln \left(q_{e}-q_{t}\right)=\ln \left(q_{e}\right)-k_{1} t$

where $k_{1}$ is the pseudo-first order rate constant ( $\left.1 / \mathrm{min}\right)$. The pseudo-second order equation is:

$$
\frac{t}{q_{t}}=\frac{t}{q_{e}}+\frac{1}{k_{2} q_{e}^{2}}
$$

where $\mathrm{k}_{2}$ is the pseudo-second order rate constant (g/mg/min).

\section{Adsorption isotherms}

To fit data using isotherms, the equilibrium adsorption was found at several different initial concentrations at a fixed time. The concentrations used were $1 \mathrm{mg} / \mathrm{L}, 5 \mathrm{mg} / \mathrm{L}, 10 \mathrm{mg} / \mathrm{L}, 25 \mathrm{mg} / \mathrm{L}$, and 50 $\mathrm{mg} / \mathrm{L}$, all at a $\mathrm{pH}$ of $5 \pm 0.25$. The equilibrium adsorption was tested using the same method previously discussed.

Adsorption isotherms are essential to determine the mechanism of adsorption. In this paper, two different models are tested, Langmuir and Freundlich. The Langmuir isotherm is one of the most commonly used adsorption models. While it was originally used to model gas adsorption, it is also commonly used for solid-liquid adsorption. ${ }^{42}$ Langmuir adsorption assumes that there is monolayer adsorption and that there is a limited number of adsorption sites. ${ }^{43}$ The Langmuir model is expressed as:

$\mathrm{q}_{\mathrm{e}}=\frac{\mathrm{q}_{\mathrm{m}} \mathrm{K}_{\mathrm{l}} \mathrm{C}_{\mathrm{e}}}{1+\mathrm{K}_{\mathrm{l}} \mathrm{C}_{\mathrm{e}}}$

where $\mathrm{q}_{\mathrm{e}}(\mathrm{mg} / \mathrm{g})$ is the adsorption capacity at equilibrium, and $\mathrm{C}_{\mathrm{e}}(\mathrm{mg} / \mathrm{L})$ is the concentration of dye adsorbed at equilibrium; $\mathrm{q}_{\mathrm{m}}(\mathrm{mg} / \mathrm{g})$ is the maximum amount of monolayer adsorption possible, and $\mathrm{K}_{\mathrm{l}}$ $(\mathrm{L} / \mathrm{mg})$ is a constant, which is related to the affinity of the binding sites to the adsorbate. From these values, one can predict the interaction between adsorbent and adsorbate using the separation factor: ${ }^{43}$

$\mathrm{R}_{1}=\frac{1}{1+\mathrm{K}_{1} \mathrm{C}_{0}}$

where $\mathrm{C}_{0}(\mathrm{mg} / \mathrm{L})$ is the initial concentration of dye. If $\mathrm{R}_{1}$ is greater than one, adsorption is unfavorable. ${ }^{44}$ If it is equal to one, adsorption is linear, and if $R_{1}$ is in between zero and one, adsorption is favorable. ${ }^{44}$ If the separation factor is equal to zero, the adsorption is irreversible. $^{44}$

The Freundlich isotherm model was also tested. It is important to recall that the main assumption of the Freundlich isotherm is that there is heterogeneity in the surface energy, ${ }^{45}$ and can be described by the following equation:

$\mathrm{q}_{\mathrm{e}}=\mathrm{K}_{\mathrm{f}} \mathrm{C}_{\mathrm{e}}^{\mathrm{n}^{-1}}$

where $\mathrm{K}_{\mathrm{f}}$ a constant measuring adsorption capacity and $\mathrm{n}$ is a constant that measures intensity. An $\mathrm{n}$ value between two and ten represents strong adsorption between the adsorbate and adsorbent. ${ }^{46}$

\section{RESULTS AND DISCUSSION}

\section{Thermogravimetric analysis}

Thermogravimetric analysis is a commonly used technique to view the decomposition patterns of different materials. Knowing the onset temperature is very valuable for this application, 


\section{MARSHALL FRYE et al.}

as it shows what range of temperature the filter can be used without experiencing degradation.

The first mass loss occurs at $\sim 70{ }^{\circ} \mathrm{C}$ for all 4 samples, which corresponds to the dehydration of the cellulose and results in an approximate loss of 3.5-5.6 wt $\%$ of the sample. Following this stage, another, much larger weight loss occurs. This loss in mass is the result of the decomposition of the polymer, which is accompanied by depolymerization and gas formation. The extrapolated onset temperature for this loss was approximately $281{ }^{\circ} \mathrm{C}$ for both of the nonfunctionalized samples, and it is consistent with literature. ${ }^{47}$ The sulfonated samples had a lower decomposition temperature, $210{ }^{\circ} \mathrm{C}$, for the $4 \mathrm{~h}-\mathrm{CNCxCh}$ sample and $192{ }^{\circ} \mathrm{C}$ for the $4 \mathrm{~h}-\mathrm{CNC}$ sample. For all of the samples, this decomposition led to a loss around $70 \mathrm{wt} \%$. While there is a change in the thermal stability as a result of sulfonation, there is no anticipated impact on the ability of the cellulosic filter to be used in commercial waste treatment plants, where the temperature is usually between $10^{\circ} \mathrm{C}$ and $20{ }^{\circ} \mathrm{C}$. ${ }^{48}$

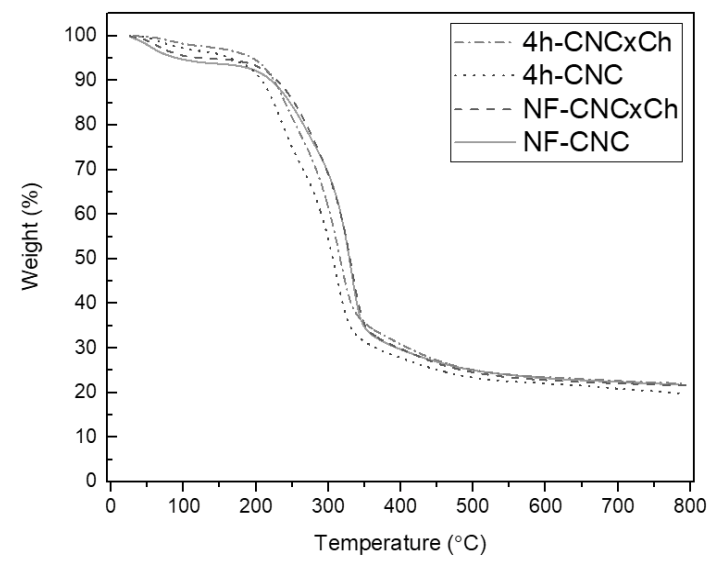

Figure 4: TGA curves of nonfunctionalized and functionalized samples with and without chitosan

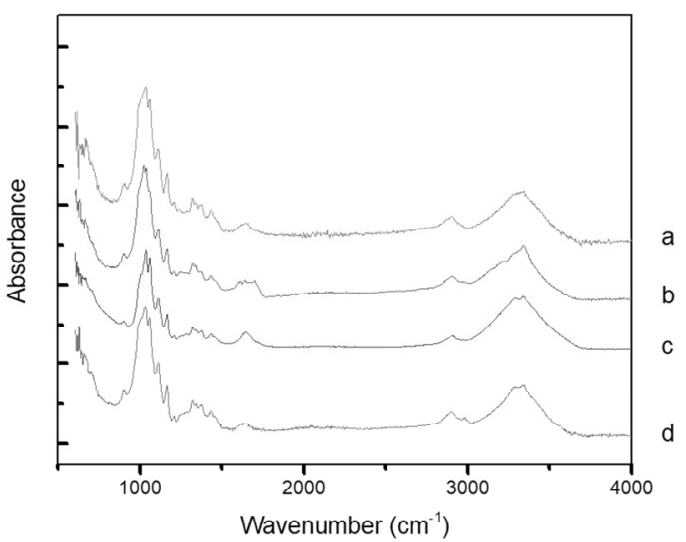

Figure 5: FTIR of a) $4 \mathrm{~h} 45^{\circ}-\mathrm{CNC}$, b) $4 \mathrm{~h}-\mathrm{CNC}$, c) Oxidized CNC, and d) NF-CNC

\section{FTIR}

FTIR is commonly used to see changes in different samples by seeing what bonds are present. In this case, the sulfonate and aldehyde bonds are being analyzed to see any changes. The

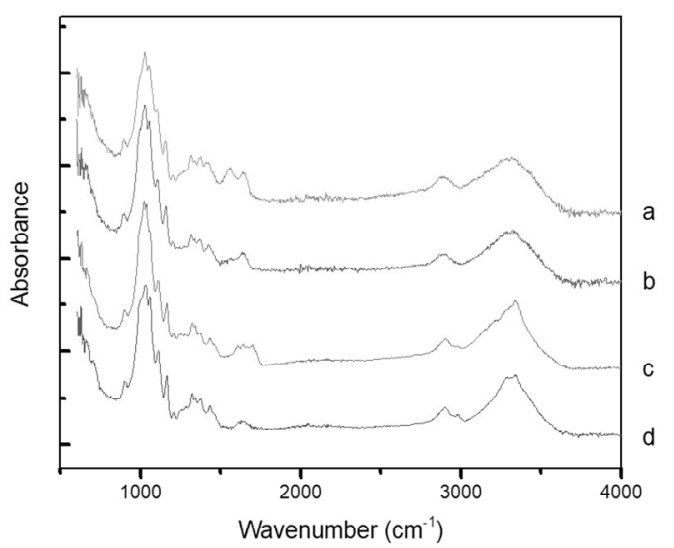

Figure 6: FTIR of a) NF-CNCxCh, b) 4h-CNCxCh, c) NF-CNC, and d) $4 \mathrm{~h} \mathrm{CNC}$

peaks at $\sim 3336 \mathrm{~cm}^{-1}$ and $\sim 2891 \mathrm{~cm}^{-1}$ correspond to the $\mathrm{O}-\mathrm{H}$ and $\mathrm{C}-\mathrm{H}$ absorption peaks, respectively. ${ }^{49}$ The peak at $\sim 1035 \mathrm{~cm}^{-1}$ have been shown to be the $\mathrm{C}-\mathrm{O}-\mathrm{C}$ vibration in the nanocellulose ring. ${ }^{50}$ All three of these peaks are 
found consistently throughout literature describing FTIR spectra of nanocellulose. ${ }^{29-31}$ The consistency of these peaks through the different samples demonstrates that the cellulose local structure is not significantly impacted by the sulfonation. The oxidation of the nanocellulose is shown by the appearance of a peak at approximately $1635 \mathrm{~cm}^{-1}$. This peak has been reported to be an aldehyde peak in cellulose. ${ }^{25}$ The shrinking of the aldehyde peak and growth of the sulfonate peak at $901 \mathrm{~cm}^{-1}$ both support that sulfonation has successfully taken place. ${ }^{51}$ It is worth mentioning that the nanocellulose purchased was processed using sulfuric acid, which does lead to the formation of sulfonate groups; which is why the sulfonate peaks at 1112 $\mathrm{cm}^{-1}$ and $1165 \mathrm{~cm}^{-1}$ are present in the nonfunctionalized sample. ${ }^{51,52}$ Overall, it is demonstrated that the oxidation and sulfonation steps of functionalization gave the desired results of a sulfonated cellulose sample. FTIR was then run to compare the samples embedded with chitosan and not in order to determine if crosslinking occurred for nonfunctionalized and functionalized samples.

As shown in Figure 6, there is broadening of the peaks around 2891 and 3336 for samples NF$\mathrm{CNCxCh}$ and $4 \mathrm{~h}-\mathrm{CNCxCh}$, possibly due to the steric hindrance caused by crosslinking and/or hydrogen bonding between the cellulose and chitosan. ${ }^{53}$ The basic chemical and local structure of the cellulose is retained, as the rest of the characteristic peaks are unchanged. Ultimately, the cellulose was functionalized via sulfonation and then further crosslinked with chitosan.

\section{SEM}

As expected, the SEM images show a layered structure in the freeze-dried nanocellulose. ${ }^{54,55}$ The SEM images show many interesting changes in the nanocellulose with varying degrees of sulfonation.

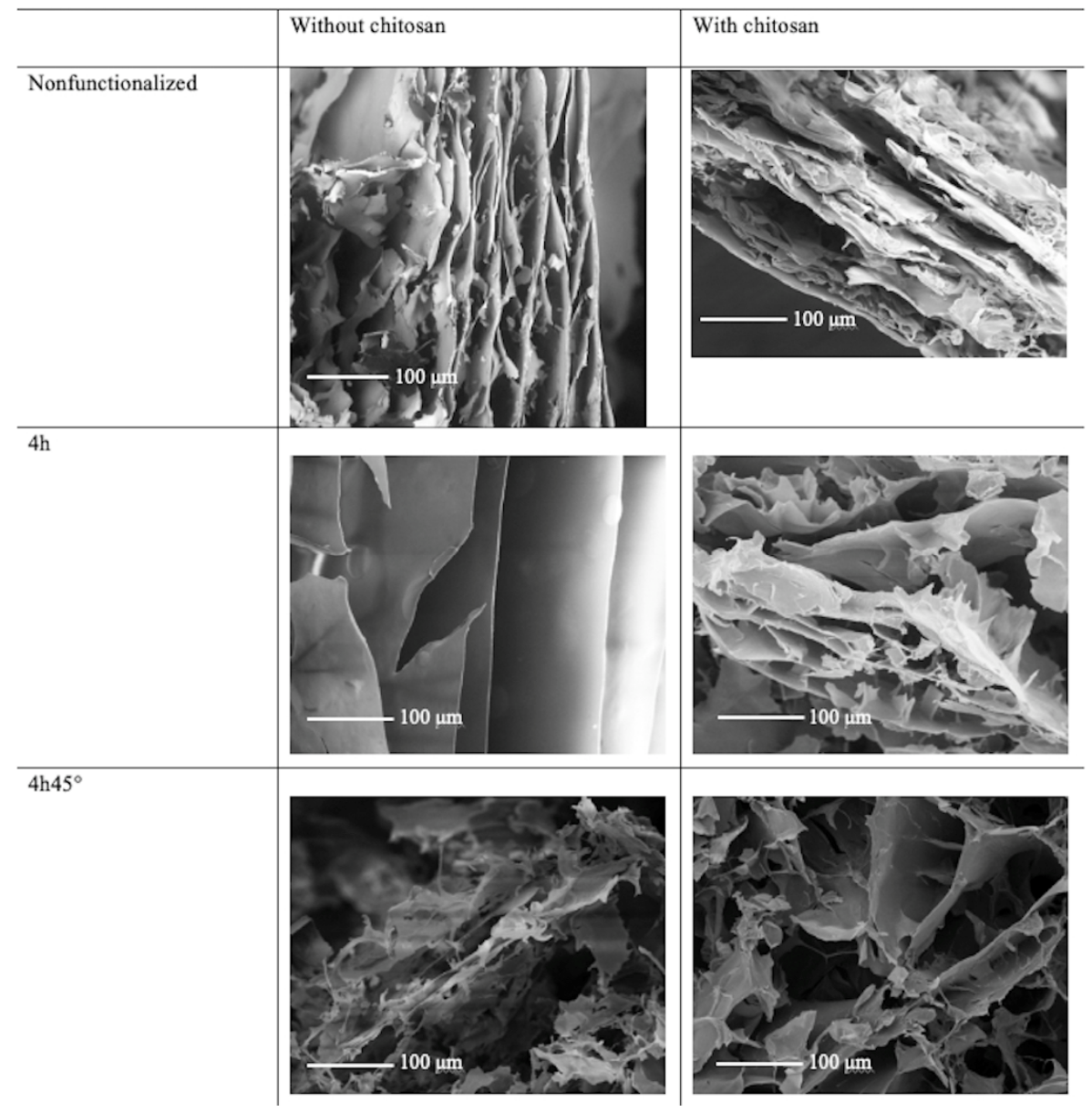

Figure 7: SEM images of nonfunctionalized, $4 \mathrm{~h}-\mathrm{CNC}$, and $4 \mathrm{~h} 45^{\circ}-\mathrm{CNC}$ nanocellulose samples, all with and without chitosan 
The 4h-CNC sample clearly has the largest separation between the layers. This separation is most likely due to the repulsion between the negative charge on the sulfonate groups. The nonfunctionalized sample still has some ordering between the layers, and the layers are much closer together than the $4 \mathrm{~h}-\mathrm{CNC}$ sample. The $4 \mathrm{~h} 45^{\circ}$ CNC sample has a barely distinguishable organizational system, which could be due to the degradation of the nanocellulose backbone from increasing the temperature during the sulfonation reaction. Cellulose degradation during this sulfonation process has been described in literature, and it is possible that increasing the temperature increased the rate of degradation. ${ }^{26}$

Crosslinking with chitosan also causes several distinguishable microstructural differences in the SEM images. The samples that were crosslinked with chitosan exhibit layers that are more closely packed than those without crosslinking. This packing is likely due to the attraction of the positively charged amino groups and the negatively charged sulfonate groups. This would also explain why the $4 \mathrm{~h}-\mathrm{CNC}$ sample had the largest change in structure. The $4 \mathrm{~h} 45^{\circ}-\mathrm{CNC}$ sample seemed to regain its structure with the crosslinking, reversing the effects of degradation.

\section{Porosimetry}

The results from porosimetry demonstrate a difference in the pore structure of the nonfunctionalized and sulfonated samples. As shown below in Figure 8, the nonfunctionalized samples exhibit more small pores than the sulfonated samples. This is most likely caused by the electrostatic repulsion between sulfonate groups separating the layers and not allowing for the small-scale pores to form. From these data, the surface area, average pore size, and pore volumes were software calculated and are shown in Table 1. These results agree with the results from the SEM, which showed smaller pores for the nonfunctionalized samples and larger pores for the sulfonated samples.

\section{Conductometric titration}

Conductometric titration has been consistently used in literature to calculate the sulfonate group content in nanocellulose. ${ }^{26,56,57}$ Figure 9 shows a representative conductometric titration curve with the fitted lines for analysis, as described in the experimental section. A representative plot is used as all results follow a similar shape. The first intersection point indicates the amount of sodium hydroxide at which all the sulfonate groups were reacted. The results of the titration experiments are summarized in Table 2 .

The results from the conductometric titration were not expected. While it was anticipated that increasing the temperature at which sulfonation occurred would increase the concentration of sulfonate groups, the opposite was observed. It is likely that the higher temperature resulted in degradation of the cellulose and thus the decrease in sulfonation compared to the samples processed at room temperature. Nonetheless, it is clear that both sulfonation conditions result in higher concentration of sulfonate groups than the nonfunctionalized samples.

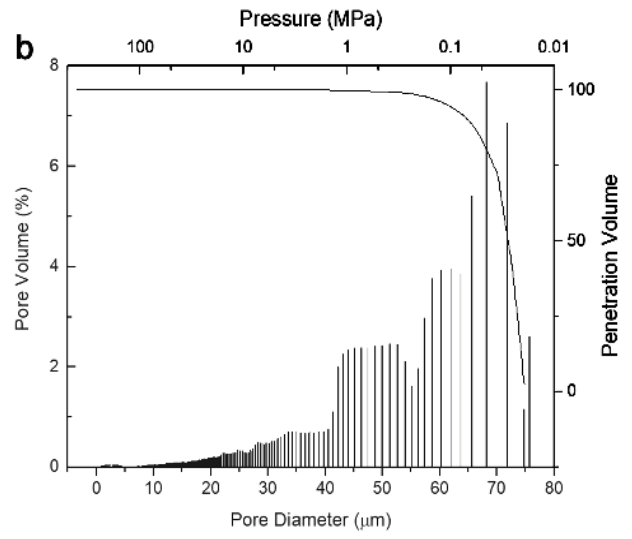

Figure 8: Porosimetry results of a) NF-CNCxCh and b) $4 \mathrm{~h}-\mathrm{CNCxCh}$ 
Table 1

MIP results of functionalized and nonfunctionalized samples

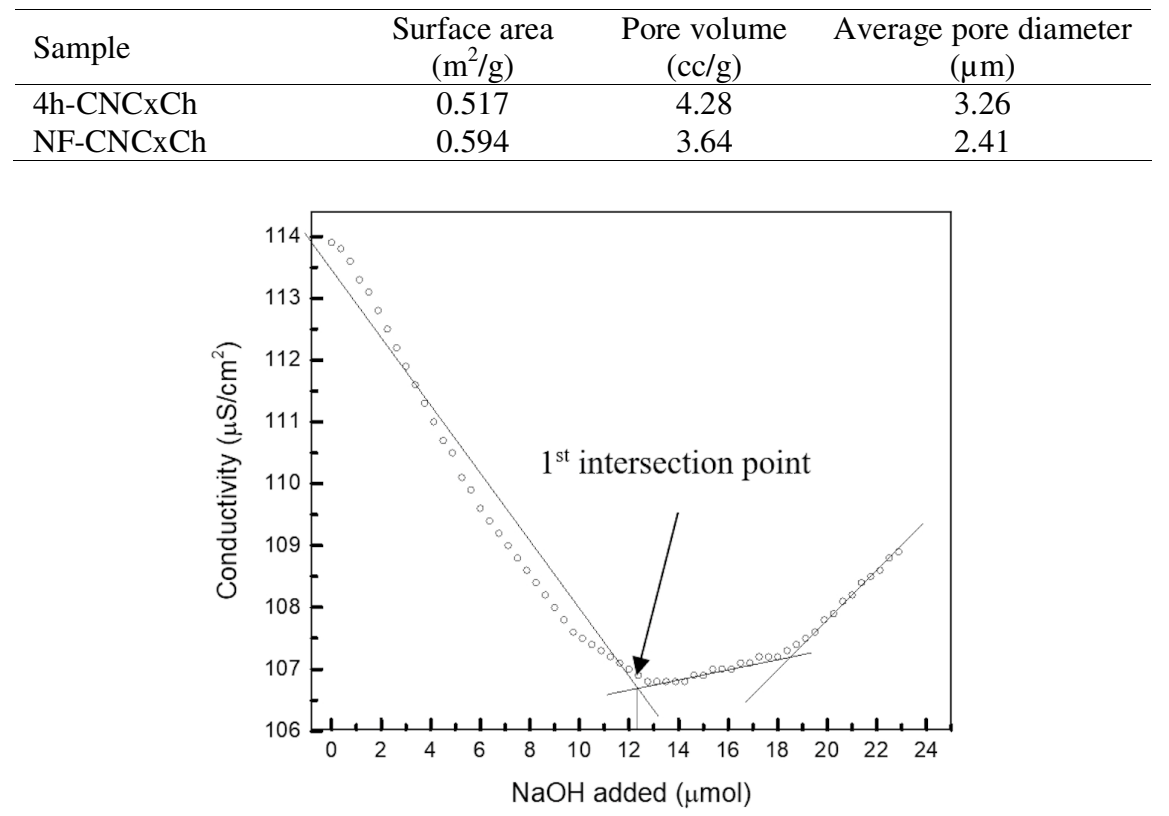

Figure 9: Example results from conductometric titration

Table 2

Results from conductometric titration of the different samples

\begin{tabular}{ll}
\hline $\mathrm{NF}-\mathrm{CNC}$ & $0.108 \mathrm{mmol} / \mathrm{g}$ \\
$4 \mathrm{~h}-\mathrm{CNC}$ & $0.194 \mathrm{mmol} / \mathrm{g}$ \\
$4 \mathrm{~h} 45^{\circ}$-CNC & $0.142 \mathrm{mmol} / \mathrm{g}$ \\
\hline
\end{tabular}

Adsorption

Adsorption kinetics

Figure 10 shows the adsorption of Victoria blue $\mathrm{R}$ by nanocellulose as a function of time.
From the curves, it can be concluded that three hours is sufficient time for the nanocellulose filters to adsorb the dye. It can also be seen that the $4 \mathrm{~h} 45^{\circ}-\mathrm{CNCxCh}$ sample has both the fastest adsorbtion kinetics and highest overall adsorption.

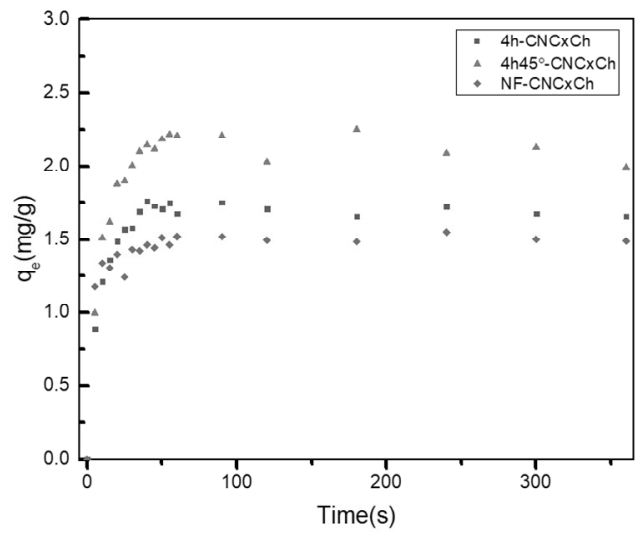

Figure 10: Adsorption of Victoria blue $\mathrm{R}$ by nanocellulose samples with varying degrees of sulfonation over time 

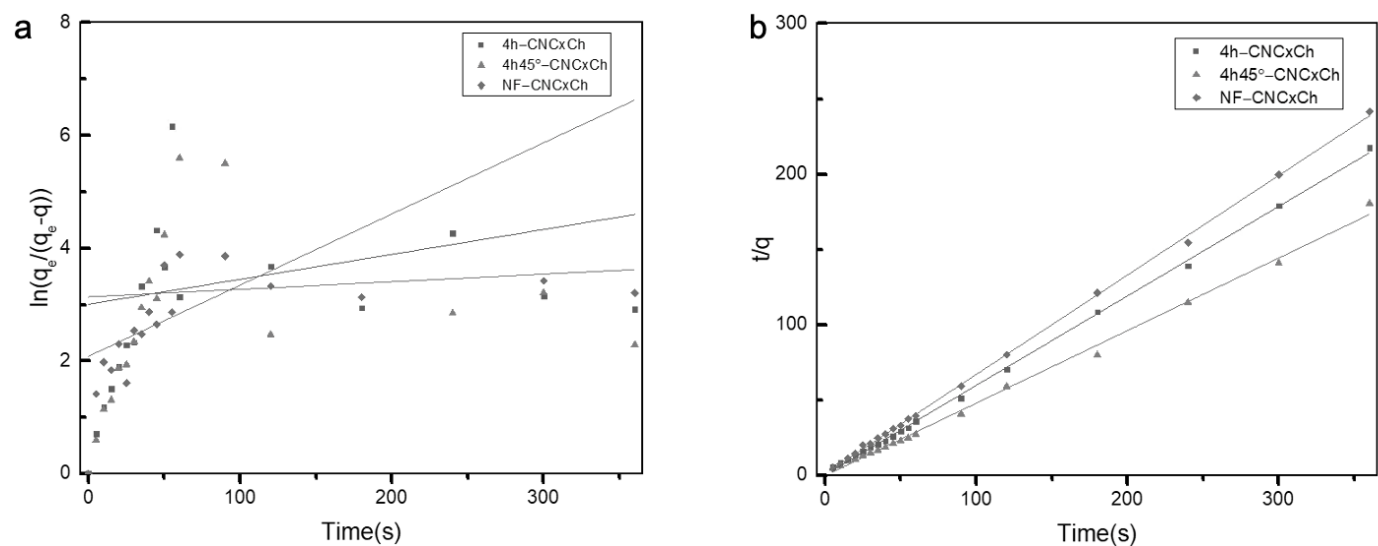

Figure 11: Plots of a) the pseudo-first order model, which was calculated using Eq. (5), and b) the pseudosecond order model, which was calculated using Eq. (6). Both of the plot were fit using a linear fit, and the coefficients of determination were compared

Table 3

Constants determined from the Langmuir and Freundlich isotherms

\begin{tabular}{lcccc}
\hline Model & Parameter & 4h-CNCxCh & $4 \mathrm{~h} 45^{\circ}-\mathrm{CNCxCh}$ & NF-CNCxCh \\
\hline \multirow{3}{*}{ Langmuir } & $\mathrm{q}_{\mathrm{m}}(\mathrm{mg} / \mathrm{g})$ & $68.56 \pm 2.79$ & $62.18 \pm 2.7$ & $15.29 \pm 1.88$ \\
& $\mathrm{~K}(\mathrm{~L} / \mathrm{mg})$ & $0.142 \pm 0.017$ & $0.0971 \pm 0.013$ & $0.151 \pm 0.062$ \\
& $\mathrm{R}^{2}$ & 0.994 & 0.996 & 0.928 \\
\hline \multirow{3}{*}{ Freundlich } & $\mathrm{K}_{\mathrm{f}}$ & $13.06 \pm 2.89$ & $10.06 \pm 2.41$ & $4.02 \pm 0.92$ \\
& $\mathrm{n}$ & $2.52 \pm 0.41$ & $2.35 \pm 0.38$ & $3.28 \pm 0.7$ \\
& $\mathrm{R}^{2}$ & 0.927 & 0.948 & 0.87 \\
\hline
\end{tabular}

Conversely, and as expected, the nonfunctionalized nanocellulose filters showed the lowest overall absorption. It is important to note that per the conductometric titration results, the 4h-CNCxCh samples had the largest concentration of sulfonate groups and therefore, were expected to exhibit higher adsorption. Nonetheless, besides morphological differences of the filters (see Fig. 7), it is possible that steric hindrance among the higher concentration of sulfonate groups prevented the effective chemical interaction with the dye in the solution. Regardless, it is confirmed that the sulfonation process is effective in increasing the adsorption over the nonfunctionalized filters.

To further analyze the adsorption data, fits to kinetic models were performed and plotted as shown in Figure 11. The pseudo-second order kinetic model, corresponding to chemisorption, fits the best (4h-CNCxCh: $\mathrm{R}^{2}=0.999,4 \mathrm{~h} 45^{\circ}$ CNCxCh: $\mathrm{R}^{2}=0.997$, NF-CNCxCh: $\mathrm{R}^{2}=$ 0.999). ${ }^{58}$ This is expected due to the strong interactions between the positively charged amine and the negatively charged sulfonate groups. By contrast, the pseudo-first order model, which correlates more to physisorption, did not fit the data (4h-CNCxCh: $\mathrm{R}^{2}=0.025,4 \mathrm{~h} 45^{\circ}-\mathrm{CNCxCh}$ : $\mathrm{R}^{2}=0.002$, NF-CNCxCh: $\mathrm{R}^{2}=0.237$ ). Based on these results, it can be concluded that the adsorption of the dye on nanocellulose is likely through chemical adsorption.

\section{Adsorption isotherm}

Adsorption isotherms were analyzed using Langmuir and Freundlich models. The fitting parameters are presented in Table 3 and provide some insight into the adsorption mechanisms taking place. Based on how the Langmuir model fits the data better, it can be inferred that there is a limited number of adsorption sites and that the adsorption is monolayer. However, the Freundlich model also fits the data fairly well and therefore it cannot be discarded all together. In both models, the constants related to the maximum adsorption were largest for the $4 \mathrm{~h}-\mathrm{CNCxCh}$ filters. Because of this, it can be assumed that the increase in sulfonate groups increases the maximum amount of dye adsorbed. In the Langmuir model, the $\mathrm{K}_{1}$ values for all samples correspond to $R_{1}$ values between 0 and 1 . This means that adsorption is favorable for the samples. In the Freundlich model, the $\mathrm{n}$ value was between two and ten for 
all levels of functionalization, representing good adsorption characteristics. All these factors lead to the conclusion that the increase in the sulfonate group content makes the $4 \mathrm{~h}-\mathrm{CNCxCh}$ sample a better adsorbent for both low and high concentrations of dye. Furthermore, it can be

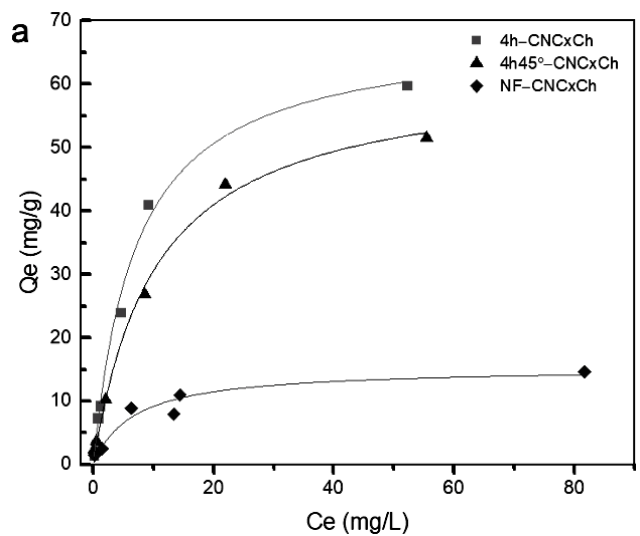

concluded that the sulfonated nanocellulose is an effective adsorbent of Victoria blue $\mathrm{R}$, when compared to other adsorbents, like magnetic microparticles and activated carbon. ${ }^{59,60}$ The adsorption capability of various cellulosic filters to sequester cationic dyes is shown in Table 4 .

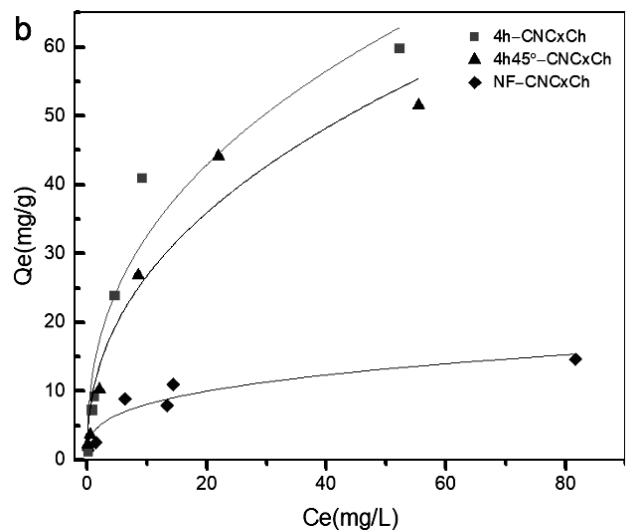

Figure 12: Plots of a) the Langmuir fit and b) the Freundlich fits of adsorption data. In both of these plots, equilibrium concentration was plotted against equilibrium adsorption capacity. Plot a was fit using Eq. (7) and plot b was fit using Eq. (9) in order to determine the isotherm constants

Table 4

Comparison of cationic dye adsorption on other cellulosic materials

\begin{tabular}{lccc}
\hline Adsorbent & Dyes removed & $\mathrm{Q}_{\mathrm{e}}(\mathrm{mg} / \mathrm{g})$ & Reference \\
\hline Magnetic cellulose ionic liquid & Congo Red & 131 & 61 \\
Tannin $\square$ immobilized cellulose microspheres & Methylene blue & 57.54 & 62 \\
& Methylene blue & 186.63 & 63 \\
Carboxylate-functionalized cellulose & Rhodamine 6G & 118.21 & \\
Activated carbon functionalized cellulose & Methylene blue & 54 & 64 \\
Sulfonated nanocellulose/chitosan composite & Victoria blue R & 68.56 & This study \\
\hline
\end{tabular}

While performance comparison across values in literature is complex and not straightforward, given the varying experimental setups and procedures followed, it is clear that the adsorption of cationic dyes onto the sulfonated nanocellulose/chitosan filters is comparable to that observed in other cellulosic sequestration systems. Overall, these results are indeed encouraging and point to the potential of the present system for further improvement.

\section{CONCLUSION}

From these results, it can be concluded that sulfonated nanocellulose is a sustainable material that can be used to remove amine dyes from water. The Victoria blue $\mathrm{R}$ dye was adsorbed by all three samples, but increasing the concentration of the sulfonate groups increased the efficacy of the adsorbent, confirming the hypothesis. Based on the results from the adsorption kinetics and isotherms, it is concluded that the dye is adsorbed in a single layer fashion and that the interaction between the dye and the filter is through chemical adsorption. The sulfonated nanocellulose had a higher maximum adsorption value than those of activated carbon and magnetic microparticles, leading to the conclusion that sulfonated nanocellulose is a better adsorbent than these materials for Victoria blue R. Due to the similarity of this amine dye and opioids, it is inferred that sulfonated nanocellulose is likely to be effective at filtering out opioids. Future studies should be done on the ability of sulfonated nanocellulose to filter out specific opioids from 
water. It would also be beneficial to test the filter's ability to sequester other common drugs, such as nicotine and caffeine, as these are not easily removed during normal wastewater treatment. All factors considered, this sulfonated nanocellulose filtration system has potential towards cheap and renewable sequestration of opioids from water. This would address an emerging contaminant that continues to pollute drinking water and is affecting wildlife.

ACKNOWLEDGEMENTS: We gratefully acknowledge Noah Molko and Oriana Otero for help with the fabrication and characterization of the nanocellulose filters. We would also like to acknowledge Elizabeth Gager for performing porosimetry on the samples.

\section{REFERENCES}

1 H. Mountford, in OECD, Paris, October 25-26, 2011 , pp. $4-6$. https://www.oecd.org/env/resources/49006778.pdf

2 United Nations, Water (2018), https://www.un.org/en/sections/issues-depth/water/

3 M. Denchak, NRDC (2018), https://www.nrdc.org/stories/water-pollutioneverything-you-need-know

4 United Nations, International Decade for Life (2015), https://www.un.org/waterforlifedecade/

5 A. V. Fuentes, M. D. Pineda and K. C. N. Venkata, $\begin{array}{llll}\text { Pharmacy (Basel), } & 6 & \text { (2018), }\end{array}$ https://doi.org/10.3390/pharmacy6020043

6 Center for Disease Control, Prescribing Practices (2019),

https://www.cdc.gov/drugoverdose/data/prescribing/pr escribing-practices.html

7 N. Dasgupta, L. Beletsky and D. Ciccarone, Am. J. Public Health, 108, $182 \quad$ (2018), https://doi.org/10.2105/AJPH.2017.304187

8 G. Kinrys, A. K. Gold, J. J. Worthington and A. A. Nierenberg, J. Int. Med. Res., 46, 927 (2018), https://doi.org/10.1177/0300060517738681

9 E. J. Cone, R. Heltsley, D. L. Black, J. M. Mitchell, C. P. LoDico et al., J. Anal. Toxicol., 37, 255 (2013), https://doi.org/10.1093/jat/bkt031

10 H. S. Smith, Mayo Clin. Proc., 84, 613 (2009), https://doi.org/10.4065/84.7.613

11 A. Jurado, N. Mastroianni, E. Vàzquez-Suñé, J. Carrera, I. Tubau et al., Sci. Total Environ., 424, 280 (2012), https://doi.org/10.1016/j.scitotenv.2012.02.074

12 A. C. Chiaia, C. Banta-Green and J. Field, Environ.

Sci. Technol., 42, $8841 \quad$ (2008), https://doi.org/10.1007/s11356-011-0495-3

13 S. Terzic, I. Senta and M. Ahel, Environ. Pollut., 158, $2686 \quad$ (2010), https://doi.org/10.1016/j.envpol.2010.04.020
14 M. K. Yadav, M. D. Short, R. Aryal, C. Gerber, B. van den Akker et al., Water Res., 124, 713 (2017), https://doi.org/10.1016/j.watres.2017.07.068

15 T. Nefau, S. Karolak, L. Castillo, V. Boireau and Y. Levi, Sci. Total Environ., 461-462, 712 (2013), https://doi.org/10.1016/j.scitotenv.2013.05.038

16 B. Kasprzyk-Hordern, R. M. Dinsdale and A. J. Guwy, Water Res., 42, $3498 \quad$ (2008), https://doi.org/10.1016/j.watres.2008.04.026

17 Water Environment Federation, Following the Flow, (2009), https://www.wef.org/globalassets/assetswef/3---resources/for-the-public/public-

information/following-the-flow-book-an-inside-lookat-wastewater-treatment.pdf

18 Center for Disease Control, Water Treatment, (2015),

https:/www.cdc.gov/healthywater/drinking/public/wat er_treatment.html

${ }^{19}$ World Health Organization, in Pharmaceuticals in Drinking-Water,

(2012), http://apps.who.int/iris/bitstream/10665/44630/1/97892 41502085_eng.pdf

20 M. M. Yazdy, R. J. Desai and S. B. Brogly, J. Pediatr. Genet., 4, $56 \quad$ (2015), https://doi.org/10.1055/s-0035-1556740

21 G. Kaushik, D. P. Huber, K. Aho, B. Finney, S. Bearden et al., Biochem. Biophys. Res. Commun., 474, 291 (2016), https://doi.org/10.1016/j.bbrc.2016.04.088 22 D. Klemm, B. Heublein, H.-P. Fink and A. Bohn, Angew. Chem. Int. Ed., 44, 3358 (2005), https://doi.org/10.1002/anie.200460587

${ }^{23}$ K. P. Y. Shak, Y. L. Pang and S. K. Mah, Beilstein J. Nanotechnol., 9, $2479 \quad$ (2018), https://doi.org/10.3762/bjnano.9.232

24 N. Mahfoudhi and S. Boufi, Cellulose, 24, 1171 (2017), https://doi.org/10.1007/s10570-017-1194-0

25 H. Liimatainen, M. Visanko, J. A. Sirviö, O. E. O. Hormi and J. Niinimaki, J. Biomacromol., 13, 1592 (2012), https://doi.org/10.1021/bm300319m

26 H. Liimatainen, M. Visanko, J. Sirviö, O. Hormi and J. Niinimäki, Cellulose, 20, 741 (2013), https://doi.org/10.1007/s10570-013-9865-y

27 H. Liimatainen, J. Sirviö, O. Sundman, O. Hormi and J. Niinimäki, Water Res., 46, 2159 (2012), https://doi.org/10.1016/j.watres.2012.01.035

28 A. D. Dwivedi, S. P. Dubey, S. Hokkanen and M. Sillanpää, Chem. Eng. J., 253, 316 (2014), https://doi.org/10.1016/j.cej.2014.05.069

29 R. Chang-Qing, Upsalla Universitet, (2017), http://uu.diva-

portal.org/smash/get/diva2:1135438/FULLTEXT01.pd $\mathrm{f}$

30 M. Jesús Dueñas-Mas, M. Laura Soriano, C. RuizPalomero and M. Valcárcel, Microchem. J., 138, 379 (2018), https://doi.org/10.1016/j.microc.2018.01.035

31 H. Voisin, L. Bergström, P. Liu and A. P. Mathew, Nanomaterials, $\quad 7, \quad 57 \quad$ (2017), https://doi.org/10.3390/nano7030057 
32 A. Errokh, A. Magnin, J.-L. Putaux and S. Boufi, Cellulose, 25, $3899 \quad$ (2018), https://doi.org/10.1007/s10570-018-1871-7

33 T. Suopajärvi, H. Liimatainen, M. Karjalainen, H. Upola and J. Niinimäki, J. Water Process Eng., 5, 136 (2015), https://doi.org/10.1016/j.jwpe.2014.06.003

34 National Institute on Drug Abuse, in Ordering Guidelines Research Chemicals Controlled Substances, (2016), https://www.drugabuse.gov/research/research-datameasures-resources/nida-drug-supply-

program/ordering-guidelines-research-chemicalscontrolled-substances

35 M. Kumar and R. Tamilarasan, Mater. Environ. Sci, 5 , 510 (2014),

http://www.jmaterenvironsci.com/Document/vol5/vol5 _N2/62-JMES-602-2014-KumarTamilarasan.pdf

$\overline{36}$ M. Kumar and R. Tamilarasan, J. Chem. Eng. Data, 58, 517 (2013), https://doi.org/10.1021/je3012309

37 Z. Karim, A.P. Mathew, M. Grahn, J. Mouzon and K. Oksman, Carbohyd. Polym., 112, 668 (2014), https://doi.org/10.1016/j.carbpol.2014.06.048

38 J. Sirvio, U. Hyvakko, H. Liimatainen, J. Niinimaki and O. Hormi, Carbohyd. Polym., 83, 1293 (2011), https://doi.org/10.1016/j.carbpol.2010.09.036

39 ASTM International, ASTM E2550, (2017), https://compass.astm.org/EDIT/html_annot.cgi?E2550 $+17$

40 I. Rocha, N. Ferraz, A. Mihranyan, M. Strømme and J. Lindh, Cellulose, 25, 1899 (2018), https://doi.org/10.1007/s10570-018-1661-2

41 Scandinavian Pulp, Paper and Board, Scandinavian Standard 65:02 (2002)

http://www.kemesta.fi/document.php/1/102/cm_6502.pdf/cf67249808953749768b08f7e2eb88af

42 N. Ayawei, A. N. Ebelegi and D. Wankasi, J. Chem., 2017, ID $3039817 \quad$ (2017), https://doi.org/10.1155/2017/3039817

${ }^{43}$ R. K. Gautam and M. C. Chattopadhyaya, "Nanomaterials for Wastewater Remediation", Butterworth-Heinemann, 2016, pp. 79-109

44 M. A. Hubbe, S. H. Hasan and J. J. Ducoste, BioResources, $\quad 6, \quad 2161 \quad$ (2011), https://ojs.cnr.ncsu.edu/index.php/BioRes/article/view/ BioRes_06_2_2161_Hubbe_HD_Removal_Pollutants_ Review_Pt1_Metals

45 X. Chen, Information, 6, 14 (2015), https://doi.org/10.3390/info6010014

46 O. Hamdaoui and E. Naffrechoux, J. Hazard. Mater., 147, $381 \quad$ (2007), https://doi.org/10.1016/j.jhazmat.2007.01.021

47 M. M. Beppu, R. S. Vieira, C. G. Aimoli and C. C. Santana, J. Membrane Sci., 301, 126 (2007), https://doi.org/10.1016/j.memsci.2007.06.015
48 Toprak, Wastewater, (2006), http://web.deu.edu.tr/atiksu/ana52/4ani.html

49 W. T. Wulandari, A. Rochliadi and I. M. Arcana, IOP Conf. Ser.: Mater. Sci. Eng., 107, 012045 (2016), https://doi.org/10.1088/1757-899X/107/1/012045

50 A. Mandal and D. Chakrabarty, Carbohyd. Polym.,

86, 1291

(2011),

https://doi.org/10.1016/j.carbpol.2011.06.030

51 J. P. S. Morais, M. de F. Rosa, M. de Souza Filho, L. D. Nascimento et al., Carbohyd. Polym., 91, 229 (2013), https://doi.org/10.1016/j.carbpol.2012.08.010

52 P. Lu and Y.-L. Hsieh, Carbohyd. Polym., 82, 329 (2010), https://doi.org/10.1016/j.carbpol.2010.04.073

53 I. A. Udoetok, L. D. Wilson and J. V. Headley, ACS Appl. Mater. Interfaces, 8, 33197 (2016), https://doi.org/10.1021/acsami.6b11504

54 Y. Peng, D. J. Gardner and Y. Han, Cellulose, 19. 91 (2012), https://doi.org/10.1007/s10570-011-9630-Z

55 J. Han, C. Zhou, Y. Wu, F. Liu and Q. Wu, Biomacromolecules, 14, $1529 \quad$ (2013), https://doi.org/10.1021/bm4001734

56 J. Zhang, N. Jiang, Z. Dang, T. J. Elder and A. J. Ragauskas, Cellulose, 15, 489 (2007), https://doi.org/10.1007/s10570-007-9193-1

57 K. Zhang, E. Brendler, A. Geissler and S. Fischer, Polymer, 52, 26 (2011), https://doi.org/10.1002/15213935(20001001)201:15\%3C1950::AIDMACP1950\%3E3.0.CO;2-3

58 Z. Reddad, C. Gerente, Y. Andres and P. Le Cloirec, Environ. Sci. Technol., 36, 2067 (2002), https://doi.org/10.1021/es0102989

59 M. Kumar, R. Tamilarasan and V. Sivakumar, Carbohyd. Polym., 98, $505 \quad$ (2013), https://doi.org/10.1016/j.carbpol.2013.05.078

60 K. Erol, K. Köse, D. A. Köse, Ü. Sızır, İ. T. Satır et al., Desalin. Water Treat., 57, 9307 (2016), https://doi.org/10.1080/19443994.2015.1030708

61 M. H. Beyki, M. Bayat and F. Shemirani, Bioresour. Technol., 218, $326 \quad$ (2016), https://doi.org/10.1016/j.biortech.2016.06.069

62 Y. Pei, X. Wu, G. Xu, Z. Sun, X. Zheng et al., J. Chem. Technol. Biotechnol., 92, 1276 (2017), https://doi.org/10.1002/jctb.5121

63 D. Tian, X. Zhang, C. Lu, G. Yuan, W. Zhang et al., Cellulose, 21, $473 \quad$ (2014), https://doi.org/10.1007/s10570-013-0112-3

64 S. Moosavi, S. Gan and S. Zakaria, Cellulose Chem. Technol., 53, $815 \quad$ (2019), https://doi.org/10.35812/CelluloseChemTechnol.2019. 53.80 